\title{
Psychiatric implications of chronic civilian strife or war: Northern Ireland
}

\author{
Peter S. Curran \& Paul W. Miller
}

This is the first paper in a series considering the implications for psychiatric services of chronic civilian strife or war. Ideas for further papers are welcome: please write to Dr Gwen Adshead or Gillian Blease at the Royal College of Psychiatrists, 17 Belgrave Square, London SW1X 8PG.

\footnotetext{
"Sectarianism lives in all of us - it is in the choices we make, it is in the words we say, it is even in the friends we make. It lives in our churches and it taints our community life. It makes possible the violent actions which we abhor" (McKittrick et al, 1999).
}

As Northern Ireland celebrates the first year in 30 years when a soldier or police officer has not been killed and as it currently struggles to implement yet another political initiative to gain peace, now seems an appropriate time to reflect upon the effect of political violence on the psychiatric services in the province. For almost two generations the campaign of political violence has touched every doctor professionally. Indeed, one of us was a houseman in the front line Royal Victoria Hospital and the other was just born when the sectarian street pogroms and internecine violence first erupted. Neither of us knew that what was to follow would determine our professional futures. In the fresh air of the new millennium, and particularly following the horror of the Omagh massacre of August 1998 and the hope of the Good Friday agreement of April 1998, we can reflect upon and review the psychiatric aspects of politically inspired violence.

\section{Professional life}

Despite the history of civil violence and disorder there has never been a shortage of (albeit largely local) admirably qualified candidates for both junior and senior psychiatric posts. Psychiatric hospital and community facilities in the province are generous compared to those in Great Britain and we have been spared the savage pruning in services and the directions professional life has taken in other parts of the UK. The moves to general hospital units and community psychiatry have been less precipitous and more planned than in Great Britain, as local services and the planners have waited to observe the benefit/loss ratio of mainland experiments.

Doctors generally are well thought of in the province and have not had to endure the threats to which other professional groups and individuals have been subjected. None the less, almost every major hospital campus has been sometime visited by violence.

Our colleagues in accident and emergency medicine, orthopaedics, neurosurgery, plastic and general surgery have developed an expertise in the management of emergencies matched, sadly, only by our forensic scientists and pathologists. Similarly, in psychiatry each of us has gathered the experience of dealing with victims of violence, learned best classification systems of psychological reactions to trauma and developed treatment techniques to best apply in different and individual circumstances.

Peter Curran is a consultant psychiatrist at the Mater Infirmorum Hospital, Belfast, a former member of the Mental Health Commission and current member of the Sentence Review Commission. He is currently the President of the Northern Ireland Medicolegal Society. Paul Miller is a specialist registrar in psychiatry at the Mater Infirmorum Hospital, Crumlin Road, Belfast and a clinical research fellow at the Queen's University of Belfast. He is currently engaged in the Genetic Epidemiology of Mental Illness in Northern Ireland (GEMINI) research project. 


\section{History}

The different phases of what the Provisional IRA call "the Long War" and citizens colloquially call "the Troubles" brought different psychological effects or issues. Throughout the late 1960s and early 1970s there was widespread public disorder and street rioting, with neighbourhood pogroms and intimidation and a rapidly escalating murder rate. Sectarian gangs readily found innocent targets in the opposing community, since people are easily identified and political assumptions made about them merely from their address, name or school background. There was much fear and people, of necessity, scurried to the comparative safety of the ghettos, at the expense of increasing sectarianism and with growing reliance on the paramilitary organisations forming within. The Republican movement launched a bombing campaign against civic targets, bringing terror and mayhem to town centres and fear to the citizenry. They were matched in their savagery by Loyalist paramilitary retaliation.

The entry of the British army initially as broker between the two communities and the 1972 proroguing of the failed local Stormont Parliament provided each paramilitary organisation with fresh reason for renewed barbarity. The death rates for that period (Table 1) reflect the changing phases of the conflict over the 30 years. Internment failed as a military strategy, as did a series of political initiatives and strategies. More selective targeting of the security forces and members of opposing organisations and the switch of the bombing campaign to mainland Britain led to a reduction in the local murder rate and to what a Home Secretary, Reginal Maudling, infamously described as an "acceptable level of violence" (see Curran, 1988).

In more recent years the apparent acceptance by the paramilitary organisations of the futility of violence, their cease-fires and their tentative move

Table 1 Death rates for Northern Ireland, 1969-1997 (adapted from McKittrick et al, 1999)

\begin{tabular}{|c|c|c|c|c|c|c|c|}
\hline Year & Civilian & Police & Military & $\begin{array}{l}\text { Republican } \\
\text { paramilitaries }\end{array}$ & $\begin{array}{c}\text { Loyalist } \\
\text { paramilitaries }\end{array}$ & Other & $\begin{array}{c}\text { Annual } \\
\text { total }\end{array}$ \\
\hline 1969 & 14 & 1 & 0 & 2 & 1 & 0 & 18 \\
\hline 1970 & 19 & 2 & 0 & 6 & 0 & 2 & 29 \\
\hline 1971 & 94 & 11 & 49 & 23 & 3 & 2 & 182 \\
\hline 1972 & 258 & 17 & 134 & 74 & 11 & 9 & 503 \\
\hline 1973 & 132 & 13 & 67 & 38 & 13 & 4 & 267 \\
\hline 1974 & 206 & 15 & 51 & 24 & 6 & 33 & 335 \\
\hline 1975 & 173 & 11 & 22 & 31 & 28 & 13 & 278 \\
\hline 1976 & 220 & 24 & 30 & 17 & 13 & 9 & 313 \\
\hline 1977 & 55 & 14 & 29 & 8 & 7 & 5 & 118 \\
\hline 1978 & 46 & 10 & 23 & 7 & 0 & 2 & 88 \\
\hline 1979 & 44 & 14 & 47 & 9 & 2 & 16 & 132 \\
\hline 1980 & 45 & 9 & 20 & 5 & 2 & 9 & 90 \\
\hline 1981 & 53 & 21 & 24 & 16 & 3 & 2 & 119 \\
\hline 1982 & 47 & 12 & 39 & 7 & 5 & 3 & 113 \\
\hline 1983 & 28 & 18 & 15 & 8 & 2 & 9 & 80 \\
\hline 1984 & 38 & 9 & 19 & 12 & 1 & 8 & 87 \\
\hline 1985 & 23 & 23 & 6 & 5 & 0 & 2 & 59 \\
\hline 1986 & 34 & 12 & 12 & 6 & 2 & 0 & 66 \\
\hline 1987 & 45 & 16 & 11 & 26 & 6 & 2 & 106 \\
\hline 1988 & 40 & 6 & 34 & 16 & 4 & 5 & 105 \\
\hline 1989 & 38 & 9 & 26 & 3 & 3 & 4 & 83 \\
\hline 1990 & 47 & 12 & 18 & 6 & 1 & 3 & 87 \\
\hline 1991 & 63 & 6 & 13 & 14 & 7 & 1 & 104 \\
\hline 1992 & 64 & 4 & 7 & 13 & 2 & 5 & 95 \\
\hline 1993 & 68 & 6 & 8 & 4 & 3 & 4 & 93 \\
\hline 1994 & 52 & 3 & 3 & 3 & 8 & 0 & 69 \\
\hline 1995 & 8 & 0 & 0 & 0 & 1 & 0 & 9 \\
\hline 1996 & 10 & 0 & 1 & 7 & 3 & 3 & 24 \\
\hline 1997 & 12 & 4 & 1 & 1 & 3 & 1 & 22 \\
\hline 1998 & 52 & 1 & 0 & 1 & 3 & 2 & 59 \\
\hline 1999 & 6 & 0 & 0 & 0 & 1 & 0 & 7 \\
\hline Totals & 2034 & 303 & 709 & 392 & 144 & 158 & 3740 \\
\hline
\end{tabular}


towards politics, combined with public weariness of the Long War, have led to new hopes and initiatives. However, we have a communal legacy to come to terms with: 3740 dead, thousands bereaved, countless thousands injured and many embittered and unforgiving survivors. Many former paramilitarists have switched to frank criminality and establishing drug empires, while the political objection of Republicans to the state police force allows them to adopt a role in 'restorative justice', physically punishing, expelling and banishing those they judge as socially deviant.

\section{Impact on services}

"Conflicts based on political, ethnic, cultural and religious differences are rapidly replacing the international tensions of the cold war era" (Professor Mari Fitzduff, quoted by G. Grattan, Belfast Telegraph, 15 March 2000).

We have previously commented on the apparently limited impact of the Troubles on conventional psychiatric services (Curran, 1988). The Mater Infirmorum Hospital serves the catchment area of North and West Belfast, containing half the population of the city of Belfast. It is an area of very high social deprivation, unemployment, housing and population density and social pathology. The region is characterised by a series of culturally polarised housing estates and politically opposed communities, each area boasting flags, bunting, murals and painted kerbstones, as much to claim its territorial and cultural loyalty as to annoy and provoke the opposition. The interfaces are the new battlegrounds for internecine community insult and attack. Yet, in an internal audit of the Mater Infirmorum Hospital's general (National Health Service) (NHS) psychiatric practice we found only $6 \%$ of our referrals and admissions had as their precipitants any violence-related issues. Some $94 \%$ of our clinical practice is the same as that of colleagues elsewhere in the British Isles. And yet, in our densely populated, if geographically small, catchment area of perhaps no more than 10 square miles, there have occurred one-third of all the deaths, one-third of all the injuries and one-third of all the incidents of criminal and terrorist violence in the whole province over 30 years.

This figure of $6 \%$ has a resonance elsewhere. Lyons (1974) followed-up 100 individual victims of various bomb explosions and found that only $4 \%$ required psychiatric admission. Sims, in a smaller study of victims of the Birmingham bomb, found that 5\% required psychiatric help (see Curran, 1988). In a large survey of 499 criminal injury litigants who had each been victim of a variety of acts of terrorist and criminal violence, we found that $4.5 \%$ required psychiatric in-patient admission, while $11 \%$ graduated to NHS out-patient services (Kee et al, 1987). In our most recent survey of 2191 victims, $2 \%$ were admitted and $13 \%$ referred to either psychiatric out-patients, community psychiatric nurses or counselling services (further details available from the author upon request).

Just because someone experiences or witnesses an act of violence does not mean that he or she will inevitably develop psychiatric morbidity. Indeed, we have previously described (Kee et al, 1987) how 6\% of victims had insufficient clinical evidence to warrant any diagnosis, while a further $7 \%$ had mere acute reactions to stress lasting no more than days. The classifications applied in the 1987 study (Box 1)

Box 1 Classification of psychological reactions to trauma

Non-pathological reaction

Acute reaction to stress

Adjustment disorder:

- brief depressive reaction

- prolonged depressive reaction

- mixed anxiety/depressive reaction

- mixed with irritability/anger

- conduct disorder

Anxiety state:

- generalised anxiety disorder

- mixed anxiety and depressive state

Phobic illness:

- agoraphobia without panic

- agoraphobia with panic

- social phobia

- specific phobia

Psychotic or paranoid reaction

Hysteria

Depressive state

Others:

- exacerbation of pre-existing mental illness

- exacerbation of personality traits

- neuropsychiatric effects of concussion, head injury, brain damage, epilepsy

- alcohol and substance misuse

Post-traumatic stress disorder (after 2 years label as 'enduring personality change after catastrophic experience') 
Table 2 Diagnoses of 499 victims of violence (Kee et al, 1987)

$\begin{array}{lr}\text { Diagnosis } & \text { \% of victims } \\ \text { Non-pathological reaction } & 6 \\ \text { Acute reaction to stress } & 7 \\ \text { Adjustment disorders } & 36 \\ \text { Anxiety state } & 31 \\ \text { Phobic illness } & 1 \\ \text { Psychotic or paranoid states } & 0 \\ \text { Hysteria } & 1 \\ \text { Depressive states } & 17 \\ \text { Other sequelae (including } & 1 \\ \quad \text { exacerbation of pre-existing } & \\ \text { mental illness and personality traits, } \\ \quad \text { neuropsychiatric effects of concussion, } \\ \text { head injury, brain damage, epilepsy) }\end{array}$

used ICD-9 (World Health Organization, 1978), which did not allow for a diagnosis of post-traumatic stress disorder (PTSD). The results are shown in Table 2. However, examining the same cohort of 499 victims under DSM-III-R (American Psychiatric Association, 1987) we determined that $23 \%$ had a diagnosis of PTSD (Kee et al, 1987), a proportion in keeping with the $20-30 \%$ quoted in a recent paper by Adshead (2000).

In community surveys, Cairns \& Wilson (1989) reveal that the population deals effectively with the stress of continuing political violence, possibly by denial (Cairns \& Wilson, 1984). They also found that coping is more related to a person's perception and appraisal of violence than its actual level.

Throughout the province, in both urban and rural practice, our in-patient admission rates, out-patient attendance rates and psychotropic drug prescription rates are broadly comparable to similar districts in Great Britain. Our people who commit parasuicidal acts seem to do so by reason of the same litany of life's vicissitudes as anywhere else. Interestingly, our completed suicide rate halved when the Troubles first broke out in 1969 and remained low for the next few years, when the homicide rate was high (Table 1 ). This reflects international experience in several arenas of war over 100 years and invokes Durkheim's (1897) observation that there is an inverse relationship between homicide and suicide rates. However, since 1975 we have experienced exactly the same rise in male, and especially young male, suicide rates as has been noted elsewhere in Europe. In psychological post-mortem studies and observations we have not noted any correlation between the community violence and the personal circumstances of the victims of completed suicide and we assume the reasons for the high suicide rate are similar to those in other jurisdictions.
And yet this society has mutilated and ravaged itself for 30 years, visited quite indescribable acts of barbarity on its neighbours and created even more sectarianism and polarisation than previously existed. Every doctor has had patients who have been physically and emotionally wounded and who have witnessed direct acts of violence or the indirect sequelae of violence. Many thousands of people have been the primary victims of violence and every psychiatrist has examined and nursed and shared the pain of people intimidated, abused, bereaved, tortured or maimed. But the services have not been swamped, except on occasions by the sheer numbers involved, such as after the Omagh and Enniskillen bombs. We, the citizenry and the professionals alike, seemed to have learned to cope, whether by some individual psychological process or by using the plethora of voluntary, self-help support organisations that have blossomed over the years.

Currently, in the new dispensation of political hope, there is debate and speculation as to the need for a formal peace and reconciliation forum, such as happened in South Africa. Some argue that the public opportunity for individuals' cathartic expression of their feelings would prove therapeutic for the individuals and reparative for the public, but many others consider that such a forum would be exploited by the anti-agreement faction and used to express further bitterness and foment sectarian attitudes.

\section{Why is there no apparent increase in psychopathology?}

We have previously speculated (Curran, 1988) on the range of explanations for the fact that our services have not been overtaken by the enormity of individual and community emotional pain that it is assumed must have arisen because of the violence

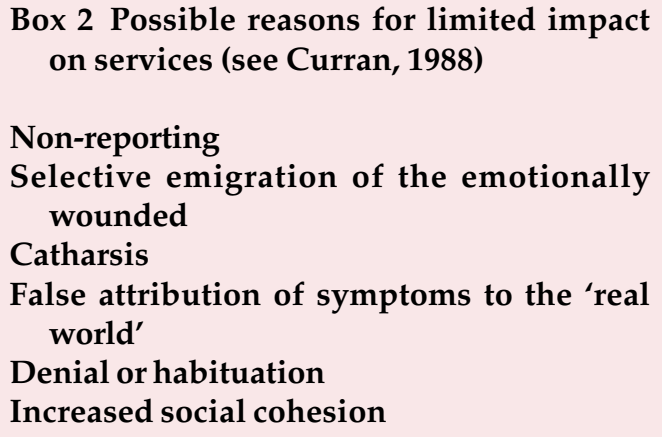

Box 2 Possible reasons for limited impact on services (see Curran, 1988)

Non-reporting

Selective emigration of the emotionally wounded

Catharsis

False attribution of symptoms to the 'real world'

Denial or habituation

Increased social cohesion 
(Box 2). Possibly individuals do not report to the caring agencies, on the assumption that little or nothing can be done for emotional pain rooted in the reality of their circumstances. Perhaps, over the years, the emotionally wounded and hurt have selectively emigrated and are no longer part of local epidemiology. Some believe that taking part in violence, being involved in politics or being a member of a paramilitary organisation, having an emphatic political view and expressing feelings including anger, are all cathartic and psychologically healthy. Many people with neurotic disorders who otherwise would have visited our psychiatric clinics in peaceful times may falsely attribute their symptoms not to personal intrapsychic conflicts, but to the harsh and violent real world around them and do not present to us. Psychologically, perhaps the citizens, including doctors and psychiatrists, lawyers and police personnel, have all become habituated to the reality and the concomitants of violence and become case-hardened. Certainly, as doctors who have directly examined thousands of victims, we are aware of this, although we are unsure whether it is denial or habituation that we employ to self-protect against the horror within the histories we have gathered. In a recent paper, Turner (2000) discussed the issue of vicarious traumatisation of therapists and listed hopelessness, omnipotence, punishment and avoidance as the countertransference feelings they experience.

We have also argued previously (Curran, 1988) that increased social cohesion within subpopulations may partly explain the phenomenon of the apparently modest impact of the Troubles on our local health services. Over the years, selfselecting communities have come together for protection. They may gather in the increasingly subcultural homogeneous working-class estates, albeit at the expense of increased sectarianism and rule by paramilitary organisations posing as defence forces united against a common enemy, real or supposed. They may form social, occupational, recreational or class groups. They may even set up victim groups. Whatever the socially binding group each of us has determined for ourselves over the 30 years, it may serve as a psychologically useful device when all around us others have wished, visited or threatened us with evil and malice. We imagine that, just as in the Second World War Londoners gathered 'underneath the arches' of the underground gained individual strength from the camaraderie, and just as the Franco-Prussian people bonded closer in nationhood during their earlier wars, so also have the various sub-populations of Northern Irish society gained strength and mutual support from whatever their source of social cohesion between 1969 and 1999.

\section{Children of the Troubles}

"War loves to seek its victims in the young" (Sophocles (c.496-406 BC), Scyrii. Frag. 507).

The experience of our colleagues in child and adolescent psychiatry has been broadly similar. Most diagnostic and treatment issues in child psychiatry are the same as they are elsewhere in the UK, and particularly in Belfast reflect emotional problems associated with inner-city life. On the occasions of major bombings or shooting massacres, such as Shankhill, Greysteel and Loughinisland, there was an increase in referrals of affected children and their families, approximating to $10 \%$ of the workload at those times. In some areas outreach specialist clinics were set up to cope with those sudden increased demands. Lynch (quoted in Daly, 1999) found that although many of the experiences undergone in such incidents mirrored those of children involved in other stressful events, prolonged exposure to the conflict and frequent reminders, such as media reporting and increased security force presence, exacerbated children's symptomatology. These children included those who had witnessed a shooting, often of a family member, had been involved in a bombing, with or without physical injury, and had been held captive or hostage. The majority suffered PTSD. In many cases school performance deteriorated. Preschool children, for whom diagnosis is difficult, often exhibited behavioural problems such as disobedience, disruptiveness, overactivity and distractibility, as well as positive symptoms of PTSD (e.g. sleep and distorted dream disturbance). Symptoms of anxiety and depression were common in all ages and several experienced grief reactions following loss of relatives. In many cases parents were unable to offer support to their children because they also were suffering from the effects of the trauma and loss. For some families, mistrust of the security forces and/ or fear of the paramilitaries were additional stressors.

While studies of clinic attenders have found that many children directly exposed to violent incidents are likely to be severely affected, for children in the community not directly exposed the situation is less clear. A school-based community study currently underway may help clarify this. Fifteen months after the Omagh bombing of August 1998, 4500 children aged between 8 and 18 years completed screening questionnaires designed to assess symptoms of traumatic stress and anxiety. Preliminary results suggest considerable disturbance for a significant minority of children.

The psychological impact of horrific paramilitary beatings that some children and adolescents have endured has yet to be studied. 


\section{Treatments in psychotraumatology}

Treatments for PTSD (including debriefing) have been reviewed in several publications (Foa et al, 1989; Shapiro, 1989; van der Kolk et al, 1996; Wessely et al, 1998; Mayou et al, 2000; Turner, 2000). Here we present just one model of psychological intervention, offerred by van der Hart et al (1989). They provide a useful therapeutic skeleton (after Pierre Janet, see Box 3 ) listing the five phases of treating PTSD.

\section{Stabilisation}

Stabilisation means helping the patient to manage intense emotions and the various defence mechanisms for coping with them, and educating the patient to understand what has happened and continues to happen to him or her as a consequence of the trauma. We know from our management of anxiety states that the recognition and naming of emotions enhances a patient's self-awareness and allows him or her to explore the emotions rather than just experience them, as happens in a patient with PTSD.

\section{Deconditioning}

The clinician now proceeds to the deconditioning of the traumatic memories and responses, helping the patient to move on from a position where highly emotionally charged trauma memories elicit conditioned responses. At the time of the trauma various autonomic responses are triggered in the patient, and the concomitant hyperarousal prevents normal processing of the trauma memory. The high levels of affect associated with the trauma memory result in a failure to lay it down as a semantic memory; instead, it is stored at an iconic level. Piaget summarises trauma's effects on memory in the following way:

"It is precisely because there is no immediate accommodation that there is complete dissociation of the inner activity from the external world. As the external world is solely represented by images, it is assimilated without resistance (i.e. unattached to other memories) to the unconscious ego"(Piaget, cited in MacCulloch \& Feldman, 1996)

When the memory is recalled it triggers a reexperiencing of the panic and autonomic responses. This recall occurs randomly in response to various different triggers and with each recall the strength of the conditioned response is increased. This process of recall and re-experiencing conforms to the pattern of a Pavlovian conditioned reflex. As therapists, our aim is to change the traumatic memory from an implicit to an explicit, autobiographical one.
Box 3 Treatment phases for post-traumatic stress disorder, after Pierre Janet (see van der Hart et al, 1989)

1 Stabilisation

2 Deconditioning of traumatic memories and responses

3 Restructuring of traumatic personal schemata

4 Re-establishment of secure social connections and interpersonal efficacy

5 Accumulation of restorative emotional experiences

To achieve this we introduce new information that is incompatible with the rigid traumatic memory (Foa et al, 1989). For example, the patient's memory and cognition "I am going to die" is challenged by the therapist's question, "Did you die?" As the answer is clearly "no", cognitive dissonance now exists, which the patient must resolve, and it is this process of resolution that results in healing.

\section{Restructuring of traumatic schemata}

A person's conceptualisation of self and the world is organised according to a range of relatively stable cognitive schemata, which are then used to organise the person's psychological experiences by processes of assimilation and accommodation, ensuring integrity of identity. Different experiences in the individual's life access different schemata. This is illustrated by the case of a man who developed PTSD after being shot in the course of his work as a postman. It transpired that he had served in the armed forces during the Falklands conflict and was wounded during his service there. However, he did not develop PTSD after that event. When questioned about this curious observation he remarked that in the Falklands he expected to be shot at, but it was not something he expected to face as a postman. In other words, his cognitive schema as a postman did not include coping with the experience of being shot. The process of identifying and restructuring traumatic schemata helps the patient to move on cognitively in a functional way. At this stage one must be aware that people who are multiply traumatised may activate latent self-concepts linked with past trauma and these must be examined as a part of the therapeutic process.

Re-establishment of social connections and interpersonal efficacy

The next phase of treatment is to re-establish secure social connections and interpersonal efficacy. We 
have already looked at how valuable the individual's social support network is in offering protection from the serious psychological impact of trauma. If we look at how the child copes within the family following a traumatic incident we see a cameo of how a person copes within society. Just as a child will be quite resilient if the parents are emotionally and physically available, but may present with severe and persistent problems if they are not, so too mature individuals react in relation to those in their social group within society. For this reason, the provision and restoration of social support is widely accepted as an essential element of acute intervention following trauma (van der Kolk et al, 1996). Following this observation many clinicians utilise some form of group therapy with the acutely or chronically traumatised, believing that skills and experience in working out problems in the environment of the group may be transferred to life in society.

\section{Accumulation of restorative experiences}

When we explore how our patients spend their time we note that much is taken up either dealing with the psychological sequelae of their traumatic memories or actively trying to avoid re-experiencing them, leaving relatively little time available for restitutive emotional experiences. The potential for reparation that gratifying new experiences could yield was recognised by Janet (1925), who encouraged his patients to engage in vigorous pursuits. These new experiences, being free of the sequelae of the trauma, were seen to be important in the present healing and the long-term outlook of the patient. We can see this in patients who begin to paint again or spend 'quality time' with their families, where the act of forming new memories that are not linked to or tainted by the trauma are in themselves reparative.

\section{Conclusions}

Many individuals in Northern Ireland over the past 30 years have been physically and psychologically traumatised and have suffered, often grievously. The existing health services have coped in helping those who presented to them. The rest of the (primarily not traumatised) population has apparently coped without psychiatric intervention, by whatever psychological resources, since there is little evidence of a major impact on NHS facilities. Curiously, we have noted in more recent years, when the violence has reduced somewhat, a rising trend in people seeking acknowledgement of victimhood. Society and the Government are currently addressing this.
Our experience is that the best result for an individual victim is attained by a combination of psychopharmacology and cognitive and behavioural therapies, but to be successful this must be delivered in the context of public empathy and society's acknowledgement that the victim has suffered.

\section{References}

Adshead, G. (2000) Psychological therapies for posttraumatic stress disorder. British Journal of Psychiatry, 177, 144-148

American Psychiatric Association (1987) Diagnostic and Statistical Manual of Mental Disorders (3rd edn, revised) (DSM-III-R). Washington, DC: APA.

Cairns, E. \& Wilson, R. (1984) The impact of political violence on mild psychiatric morbidity in northern Ireland. British Journal of Psychiatry, 145, 631-635.

— \& - (1989) Coping with political violence in Northern Ireland. Social Science and Medicine, 28, 621-624.

Curran, P. S. (1988) Psychiatric aspects of terrorist violence: Northern Ireland 1969-1987. British Journal of Psychiatry, 153, 470-475

Daly, O. E. (1999) Northern Ireland. The victims. British Journal of Psychiatry, 175, 201-204.

Durkheim, E. (1897) Le Suicide. Trans. as Suicide: A Study in Sociology by J. A. Spaulding \& G. Simpson. London: Routlegde \& Kegan Paul.

Foa, E. B., Steketee, G. \& Rothbaum, B. O. (1989) Behavioral/ cognitive conceptualizations of post-traumatic stress disorder. Behavior Therapy, 20, 155-176.

Freeman, H. L. (1999) Unconsciousness and post-traumatic stress disorder. British Journal of Psychiatry, 174, 79.

Janet, P. (1925) Psychological Healing, vols 1 \& 2 (first published 1919). New York: Macmillan.

Kee, M., Bell, P., Loughrey, G. C., et al (1987) Victims of violence: a demographic and clinical study. Medicine, Science and the Law, 27, 241-247.

Lyons, H. A. (1974) Terrorist bombing and the psychological sequelae. Journal of the Irish Medical Association, 67, 15-19.

MacCulloch, M. J. \& Feldman, P. (1996) Eye movement desensitisation treatment utilises the positive visceral element of the investigatory reflex to inhibit the memories of post-traumatic stress disorder: a theoretical analysis. British Journal of Psychiatry, 169, 571-579.

Mayou, R. A., Ehlers, A. \& Hobbs, M. (2000) Psychological debriefing for road traffic accident victims. Three-year follow-up of a randomised controlled trial. British Journal of Psychiatry, 176, 589-593

McKittrick, D., Kelters, S., Feeney, B., et al (1999) Lost Lives The Stories of the Men, Women and Children Who Died as a Result of the Northern Ireland Troubles. Edinburgh: Mainstream Publishing.

Shapiro, F. (1989) Efficacy of the eye movement desensitization procedure in the treatment of traumatic memories. Journal of Behaviour Therapy and Experimental Psychiatry, 20, 211-217.

Turner, S. (2000) Psychiatric help for survivors of torture. Advances in Psychiatric Treatment, 6, 295-303.

van der Hart, O., Brown, P. \& van der Kolk, B. A. (1989) Pierre Janet's treatment of posttraumatic stress. Journal of Traumatic Stress, 2, 379-395.

van der Kolk, B. A., McFarlane, A. C. \& Weisaeth, L. (eds) (1996) Traumatic Stress. The Effects of Overwhelming Experience on Mind, Body and Society. London: Guilford Press.

Wessely, S., Rose, S. \& Bisson, J. (1998) A systematic review of brief psychological interventions ("debriefing") for the treatment of immediate trauma related symptoms and the prevention of post traumatic stress disorder. Cochrane Library, 4. Oxford: Update Software. 
World Health Organization (1978) Manual of the International Statistical Classification of Diseases, Injuries and Causes of Death (9th revision) (ICD-9). Geneva: WHO.

\section{Multiple choice questions}

1. Traumatic memories:

a are highly emotionally charged

b fit easily within existing declarative schemata

c need to be converted to semantic memory during therapy

$\mathrm{d}$ are flexible and readily accommodate new information

e are stored in iconic form.

2. Fewer people than anticipated attend psychiatric services because of:

a the selective emigration of the traumatised

b the cathartic effect of involvement in violence

c denial

d non-reporting of symptoms

e habituation to violence.

3. PTSD in preschool children may be accompanied by:

a disobedience

b drug misuse

c overactivity

d disruptiveness

e distractibility.
4. As regards treatments for PTSD:

a selective serotonin reuptake inhibitors are of benefit in the acute phase

b critical incident stress debriefing has been shown to have long-term benefits

c psychodynamic therapy is widely used in Northern Ireland

$\mathrm{d}$ eye movement desensitisation and reprocessing is a 'stand-alone' therapy

e cognitive-behavioural therapy is a key component in its management in Northern Ireland.

5. Janet's treatment phases for PTSD include:

a disintegration of the traumatic memory

b restructuring of traumatic personal schemata

c deconditioning of traumatic memories and responses

d trauma narrative development

e stabilisation.

MCQ answers

\begin{tabular}{|c|c|c|c|c|}
\hline 1 & 2 & 3 & 4 & \\
\hline$T$ & a $T$ & a $\mathrm{T}$ & a & \\
\hline F & b $T$ & b F & b & $F$ \\
\hline$T$ & c $\mathbf{T}$ & c $T$ & c & $F$ \\
\hline F & d $T$ & d $T$ & d & F \\
\hline & e $\mathbf{T}$ & e $\mathbf{T}$ & e & $T$ \\
\hline
\end{tabular}

\section{The Royal College of Psychiatrists Journals on-line}

\section{Full text on-line}

\section{British Journal of Psychiatry, Psychiatric Bulletin and Advances in Psychiatric Treatment}

\section{www.rcpsych.org}

